modality of treatment. Those treated with mechanical thrombectomy with or without bridging IV-tPA composed the MT group. Patients treated with medical therapy alone with or without IV-tPA composed the standard medical treatment (SMT) group.

Results A total of 7 articles were included in final analysis. Only 2 studies had comparable data between MT and SMT. A total of 150 patients were treated with MT and 213 with SMT. Patients treated with MT had significantly lower mean age (MT, 70.7 years vs SMT, 73.5 years; $\mathrm{P}=0.0007$ ), higher mean/median NIHSS at presentation (MT, 7.4 vs SMT, 6.6; $\mathrm{P}=0.017)$ and longer time from onset of symptoms to treatment (MT, 230.3 minutes vs SMT, 154.1 minutes; P<0.0001). Intravenous alteplase was given to $45.3 \%$ of patients treated with MT and $53.1 \%$ of patients treated with SMT $(\mathrm{P}=0.152)$. The MT group was associated with a significantly higher rate of patients with occluded P1 segment (MT, 25.4\% vs SMT, $14.5 \% ; \mathrm{P}=0.012$ ) and significantly lower rate of patients with occluded P2 segment (MT, 63.3\% vs SMT, 75.8\%; P=0.012), while the rate of patients with occluded P3 segment did not differ between the two groups (MT, $11.3 \%$ vs SMT, 10.2\%; $\mathrm{P}=0.741)$. The rate of good outcome was significantly higher in patients treated with MT than in those treated with SMT (MT, 68.5\% vs SMT, 55.3\%; $\mathbf{P}=\mathbf{0 . 0 1 4}$ ). There was no significant difference in the rates of sICH (MT, 3.9\% vs SMT, 3\%, $\mathrm{P}=0.568)$ and mortality (MT, $11.8 \%$ vs SMT, $12.4 \%$, $\mathrm{P}=0.891)$. Good outcome significantly favored MT (OR, 1.78; 95\% CI, 1.11 - 2.85), while sICH and mortality did not favor any modality.

Conclusions Our systematic review demonstrated the scarcity of available studies focusing on aPCAO in literature and complete absence of prospective comparison between MT and medical therapy alone. Our pooled analysis comparing treatment modalities demonstrated better odds of good outcome in patients treated with MT in comparison to SMT, while there was no difference in sICH and mortality. However, significant differences in the characteristics of patients among the treatment groups, such as age, NIHSS, occluded segment of the PCA and time from onset of symptoms to treatment, highlight the need of further studies with comparable data.

Disclosures A. Monteiro: None. S. Khan: None. M. Waqas: None. N. Ruggiero: None. H. Rai: None. A. Baig: None. R. Dossani: None. J. Cappuzzo: None. E. Levy: 2; C; Claret Medical, GLG Consulting, Guidepoint Global, Imperative Care, Medtronic, Rebound, StimMed;. 4; C; NeXtGen Biologics, RAPID Medical, Claret Medical, Cognition Medical, Imperative Care (formerly the Stroke Project), Rebound Therapeutics, StimMed, Three Rivers Medical;. A. Siddiqui: 2; C; Amnis Therapeutics, Boston Scientific, Canon Medical Systems USA Inc., Cerebrotech Medical Systems Inc., Cerenovus, Corindus Inc., Endostream Medical Ltd., Imperative Care, Inc. Integra LifeSciences C. 4; C; Adona Medical, Inc, Amnis Therapeutics, (Purchased by Boston Scientific October 2017), Blink TBI Inc., Buffalo Technology Partners Inc., Cerebrotech Medical Systems, Inc., Cognition Medical, Endostrea.

\section{E-134 BRAIN ATROPHY AND OUTCOMES OF MECHANICAL THROMBECTOMY: A SYSTEMATIC REVIEW}

A Monteiro*, M Waqas, H Rai, A Baig, R Dossani, J Cappuzzo, E Levy, A Siddiqui. Neurosurgery, University at Buffalo Neurosurgery, Buffalo, NY
Introduction Mechanical thrombectomy (MT) for large vessel occlusion results in improved outcomes. The presence of brain atrophy may affect the outcomes of patients treated with MT given that it is an indicator of low brain reserve. We performed a systematic review of the available literature to assess whether brain atrophy is an indicator of poor outcomes in patients with acute ischemic stroke undergoing treatment with MT.

Methods We conducted a comprehensive systematic search of Pubmed, MEDLINE, EMBASE and Cochrane Library databases using keywords with Boolean operators in different combinations to increase search sensitivity and specificity ("brain atrophy"; "atrophy"; "white matter"; "thrombectomy"), following the Preferred Reporting Items for Systematic Reviews and Meta-Analyses (PRISMA) guidelines.

Results Four articles were included. Methods used to assess brain atrophy were Brain Atrophy Index (BAI), automated measurement of CSF volume, Global Cortical Atrophy scale (GCA) and Standards for Reporting Vascular changes on Neuroimaging (STRIVE) criteria. BAI was a predictor of mortality (1.81 to $1.87,95 \% \mathrm{CI} 1.16-1.87)$ after adjustments for age and white matter lesions. GCA remained as predictor of futile recanalization $(1.155,95 \% \mathrm{CI} 1.085-1.229)$ after adjustments for post-operative symptomatic intracranial hemorrhage. Adjustments for baseline mRS, prior stroke and posterior circulation did not significantly change the associations between CSF volume and worse outcomes (1.23, 95\%CI 0.83-1.84). The confounders used in adjusted ORs for brain atrophy according to STRIVE criteria were not reported, but the associations with unfavorable outcome remained similar (2.72, 95\%CI 1.25-5.91).

Conclusions The few studies available highlight the heterogeneity of imaging methodology when assessing brain atrophy and the difficulty in addressing the multiple confounders involved in the outcomes of these patients. More consistent and accurate investigation is needed before posing brain atrophy as a possible parameter to improve patient selection for MT.

Disclosures A. Monteiro: None. M. Waqas: None. H. Rai: None. A. Baig: None. R. Dossani: None. J. Cappuzzo: None. E. Levy: 2; C; Claret Medical, GLG Consulting, Guidepoint Global, Imperative Care, Medtronic, Rebound, StimMed;. 4; C; NeXtGen Biologics, RAPID Medical, Claret Medical, Cognition Medical, Imperative Care (formerly the Stroke Project), Rebound Therapeutics, StimMed, Three Rivers Medical;. A. Siddiqui: 2; C; Amnis Therapeutics, Boston Scientific, Canon Medical Systems USA Inc., Cerebrotech Medical Systems Inc., Cerenovus, Corindus Inc., Endostream Medical Ltd., Imperative Care, Inc. Integra LifeSciences C. 4; C; Adona Medical, Inc, Amnis Therapeutics, (Purchased by Boston Scientific October 2017), Blink TBI Inc., Buffalo Technology Partners Inc., Cerebrotech Medical Systems, Inc., Cognition Medical, Endostrea.

\section{E-135 ENDOVASCULAR TREATMENT OF ACUTE EXTRACRANIAL INTERNAL CAROTID ARTERY STROKE - SYSTEMATIC REVIEW AND POOLED ANALYSIS OF DATA FROM THE LAST DECADE}

\footnotetext{
${ }^{1} \mathrm{~A}$ Baig*, ${ }^{1} \mathrm{M}$ Waqas, ${ }^{2} \mathrm{~S}$ Khan, ${ }^{1} \mathrm{~A}$ Monteiro, ${ }^{1} \mathrm{H}$ Rai, ${ }^{1} \mathrm{R}$ Dossani, ${ }^{1} \mathrm{~J}$ Cappuzzo, ${ }^{1} \mathrm{~F}$ Almayman, ${ }^{1} \mathrm{~J}$ Davies, ${ }^{1} \mathrm{~K}$ Snyder, ${ }^{1} \mathrm{E}$ Levy, ${ }^{1} \mathrm{~A}$ Siddiqui. ${ }^{1}$ Neurosurgery, University at Buffalo Neurosurgery, Buffalo, NY; ${ }^{2}$ Neurosurgery, Jacobs School of Medicine and Biomedical Sciences, Buffalo, NY
} 